\title{
Does Design Thinking Run Counter to Design?
}

\author{
Shukai Wang \\ Pittspurgh Institute, Sichuan University, Chengdu, China \\ Email: 596088231@qq.com
}

How to cite this paper: Wang, S. K. (2022). Does Design Thinking Run Counter to Design? Art and Design Review, 10, 41-46. https://doi.org/10.4236/adr.2022.101004

Received: November 15, 2021

Accepted: January 11, 2022

Published: January 14, 2022

Copyright $\odot 2022$ by author(s) and Scientific Research Publishing Inc. This work is licensed under the Creative Commons Attribution International License (CC BY 4.0).

http://creativecommons.org/licenses/by/4.0/

\begin{abstract}
The world needs unity. It needs more and more people to unite and give full play to their professional skills to make things better. Innovative thinking has always been the thinking mode advocated by designers, not the result that can be achieved by a deliberate thinking mode. It contains a variety of thinking modes. It is an efficient unity of analysis and intuition, rationality and sensibility. It is not only an efficient complex, but also a whole brain thinking. This is the reason for the birth of design thinking. Design thinking is a thinking mode that encourages people to explore the essence of problems and reconstruct them. This is also a way of thinking, which helps to improve the development of design. The original intention of design thinking is to bring us a new perspective to face problems and create different solutions. It can be innovative and awesome. It plays the role of beginning and framework.
\end{abstract}

\section{Keywords}

Design Thinking, Design, Profession, Vagueness

\section{Introduction}

When I first heard the word "design thinking", in the article why design thinking is important, the author introduced us to the brief history of design thinking, which mentioned that this way of thinking can be traced back to 1969. The author is Herbert A. Simon (makhoul) then I had a question: this mode of thinking is not an old guy, but has appeared for about 50 years. But throughout the long history, human beings have designed countless masterpieces involving art, architecture and other fields. Without the reference of design thinking, can it really bring anything to design? Natasha Jen is an award-winning designer and educator. Her attitude is more direct and sharp. She delivered a speech entitled "design thinking is nonsense" at Adobe's 99u conference last year (Dawood, 2020). In her speech, she stressed that design thinking destroys design, adding that it is 
an "extremely dangerous idea". At that time, she demolished the house, and a considerable number of people seemed to agree with her. Design thinking is a systematic and people-centered method, which is used to solve complex problems in all aspects of life. This approach goes far beyond traditional concerns such as shape and layout. Unlike traditional science and engineering methods, traditional science and engineering methods deal with tasks from the perspective of technological feasibility. User needs and needs, as well as user oriented inventions, are the core of the process. This approach requires continuous feedback between the developer of the solution and the target user. Design thinkers stand in the position of end users-not only interview them, but also carefully observe their behavior. Solutions and ideas are embodied and communicated in prototype form as early as possible so that potential users can test and provide feedback long before completion or release. In this way, design thinking will produce practical results.

In addition, design thinking is a method for solving practical and creative problems. It is largely based on the methods and processes used by designers (Brown, 2019), but in fact it has evolved from a range of different fields-including architecture, engineering and business. Design thinking can also be applied to any field; it is not necessarily designed specifically. As a way of thinking, it is generally considered to have the nature of comprehensive processing ability. It can understand the background of the problem, give birth to insight and solutions, and rationally analyze and find the most appropriate solution. In contemporary design and engineering technology, as well as business activities and management, design thinking has become a part of popular vocabulary. It can also be more widely used to describe a unique way of "creative thinking in action", which has a greater and greater impact in the field of education and training in the $21 \mathrm{st}$ century. In this regard, it is similar to system thinking and is named for its unique way of understanding and solving problems.

At present, there is a trend among designers and other professionals. They hope to arouse the awareness of design thinking by introducing the teaching of design thinking into higher education. The assumption is that by understanding the conception methods and processes used by designers and the perspective of designers in dealing with and solving problems, individuals and enterprises will be able to better connect and stimulate their conception process, so as to achieve a higher level of innovation. Expect to create a competitive advantage in today's global economy.

But is this kind of idea totally right? Does design thinking really run counter to design?

\section{Way of Being a Professional Designer}

As a professional designer, Jen feels it is reasonable that his authority is challenged by the new trend of design thinking: this way of thinking is suitable for everyone. In her opinion, design is a professional work, of course, we should 
follow the principle of specialization. After learning a lot of design knowledge and accumulating rich experience over time, a person can finally be recognized as a designer. But now, a short-term design thinking course costs hundreds of dollars or hundreds of pounds, and everyone can become a designer. In this course, people will be exposed to some popular words, such as co creation, radical innovation and so on. "It's like wanting to be an Olympic athlete without training," she said (Dawood, 2020).

Her understanding of this tendency is correct. In his book, Tim Brown expounds his view that design thinking is not only applicable to designers, but also to creative employees, freelancers and leaders. They try to integrate design thinking into all levels of organizations, products or services to promote new choices for enterprises and society (Brown, 2019). This phenomenon can be said to be the opposite of popularization and specialization to some extent. Interestingly, PWR, a new media company, has a similar idea. According to PWR, design thinking is the glue between disciplines. It can maintain a magical balance between seemingly completely different fields, such as business and art, structure and chaos, intuition and logic, concept and implementation, playfulness and formality, control and authorization (PWR, 2019). Compared with Jen's point of view, design thinking is so popular that it is unprofessional. They all look at this from different angles and find that the work of design thinking is not important.

\section{Vagueness}

In Jen's view, compared with design works, design thinking is full of fuzziness, which means low visibility. She believes that this is an indescribable intangible thing. Different people have different definitions of design thinking. She is right. No two definitions are the same. More or less, they are all different. For example, Rita makhoul believes that it is a way to create innovation and solve problems to make the world a better place (Makhoul, 2018), while Rikke fris dam and Yu Siang Teo believe that design thinking is an iterative process in which we seek to understand users, challenge assumptions and redefine problems (Friis, 2020). However, although these definitions have different shells, some people believe that the core under the shell is the same. Connie malamed pointed out: "In every definition, we pay attention to the spirit of design thinking. It will reflect the excellent principles of people-centered inspired design." (Malamed, 2018). In this case, one side pays more attention to the definition itself, while the other side tries to dig deeper meaning.

Throughout the research on design thinking at home and abroad, most of the research is carried out around the design thinking method, that is, it mainly studies the methods used in the process of design thinking, such as brainstorming method, six question setting method, bionic simulation method, Gordon division method and so on. Of course, for a practical science like design, the conclusion of methodology is extremely important, but these studies are only limited to the methods of design thinking, and forget the causes of these methods, resulting 
in the disconnection between world outlook and methodology to a certain extent, in this way, the scientificity and practicability of the design thinking method obtained from these studies are greatly reduced. In fact, the study of design thinking method is only one aspect of design thinking research. To obtain a truly scientific design thinking method, we cannot rely entirely on experience, let alone fantasy, but on a deep understanding of the characteristics of design thinking itself. Why he can be so easy and skilled is because of his deep understanding of the physiological structure of cattle, this principle is also applicable to design thinking. To obtain a scientific and practical design thinking method, we must first have a deep and thorough understanding of the characteristics of design thinking. Only on the basis of a deep understanding of its characteristics, the design thinking method is scientific and practical.

For fuzziness, Jen also mentioned a small thing: notes. She believes that these notes are the result of design thinking. When describing a group of people gathered around a whiteboard covered with colored notes, Jen asked sarcastically, "what does all this mean?" Then she explained that she did not do so in her design works. She added that design is a high visibility work, which requires a lot of research, photos, images, etc. to establish a more intuitive and comprehensive understanding of anything. Nevertheless, Rafiq elmansy, a design lecturer and researcher at Northumbria University, believes that notes are just a tool to organize ideas and find connections between them. The main purpose here is to explore the problem and solution space. There are potential solutions in the relationship between these spaces. To refute Jen's remarks, elmansy does not think that notes are the key to design thinking, but only one of the auxiliary means. Finally, he concluded: "none of the above tools can work effectively without a skilled guide and experienced team to accurately identify different aspects of the problem." (Elmansy, 2020). We can see that Jen and elmansy have opposite views on the position of notes in design thinking. At present, there are also some studies on the nature of design thinking, but most of their research results are derived from the design thinking method, rather than from the in-depth and thorough analysis of the essence of design thinking. Therefore, strictly speaking, the results of these studies should be called the nature of design thinking method. Therefore, this topic mainly focuses on the nature of design thinking. Through analysis, it demonstrates the fuzzy characteristics of design thinking, and then makes an in-depth study on it. At present, the concept of "fuzzy" is also involved in the research on design thinking at home and abroad, but it mainly takes "fuzzy thinking" as a thinking method, or only limited to the research field of design thinking methods. It is completely different from the concept of "fuzziness" in the fuzziness of design thinking mentioned in this topic. The former refers to a thinking method, while the latter refers to the nature of design thinking itself.

Jen asked again, "how does a one size fits all approach apply to everything?" The method she mentioned is the famous five step process. She cited as an ex- 
ample that it is undeniable that different factors need to be considered when carrying out enterprise marketing activities for Coca Cola compared with designing refugee shelters for thousands of people around the world. Of course, a simple five step process cannot accommodate such a different situation (Dawood, 2020). She revealed that now a design thinking work, as a basic process, follows this process step by step, which becomes formulaic and runs counter to the design symbolizing freedom and creativity. On this point, Barry Katz, one of IDEO's partners, expressed his concern: "It really makes me a little nervous. I never thought it would be crystallized into a fixed method. I really worried that it would become a 'machine' and the 'five steps' you must go through." He was worried about how the public understood design thinking, just like Jane. In his opinion, design thinking should not be understood as a design method, and then tend to formalization. In fact, the process of design thinking is only part of the representation and concrete expression of design thinking. The goal of design thinking is to let people get rid of the so-called standards and processes, open up the infinite possibility of imagination and creativity, and solve problems in an innovative way (Tendar, 2020).

\section{Conclusion}

This era is becoming more and more complex. A design work is no longer so simple. We only need to focus on a building or a clock. Now the world needs to unite. It hopes that more and more people will unite and give full play to their professional skills to make things better. This is the reason for the birth of design thinking. However, this idea contradicts Natasha Jen's view that popularity means unprofessional. According to her point of view, a major requires a lot of knowledge and experience. As an experienced and respected designer, Natasha Jen also tends to pay more attention to expression, which is the goal of design. This is why she uses the definition of design thinking, notes and five-step process as evidence to prove that design thinking is vague and formulaic. From these, she believes that design thinking is so dangerous that it destroys design. In fact, Jen reflects the potential crisis of this way of thinking: more and more people are eager to turn design thinking into formulaic applications. It can be seen that innovative thinking should be novel and different. As a designer, we must dare to explore and explore boldly. The creative nature of design determines that designers must have the ability of innovative thinking, which is reflected in design activities. It plays an important role in the success of the whole design work. The same thing, the active completion full of blood and forced to do, the results are often very different. The former is easier to approach success. However, for designers, only the enthusiasm for design is still far from enough. What is more needed is the common support of design thinking and methods. Because the essence of design is a creative activity, which can create unprecedented, novel and beneficial things. The quality and success of a design often depend on the design thinking ability. Different design thinking modes can determine the designers to take different actions, resulting in different design results. Mature designers have 
the ability to control their own design thinking, and can develop and take actions according to the law of things themselves, so as to achieve success. If ordinary workers do not carry out this training, they can rarely control their thinking ability. Sometimes they decide a plan and behavior only based on their own preferences. They don't know why to do so or what are the advantages of doing so? It's easy to break away from the laws of things, and imagine, and finally get farther and farther away from the road of success.

\section{Conflicts of Interest}

The author declares no conflicts of interest regarding the publication of this paper.

\section{References}

Brown, T. (2019). Change by Design: How Design Thinking Transforms Organizations and Inspires Innovation. European Journal of Applied Sciences, 6, 45-46.

Dawood, S. (2020). Pentagram's Natasha Jen: “Design Is Not a Monster You 'Unleash' to Fix the World." Centual Media.

https://www.designindaba.com/articles/design-indaba-news/pentagram\%E2\%80\%99snata-

sha-jen-\%E2\%80\%9Cdesign-not-monster-you- $\%$ E2\%80\%98unleash $\%$ E2\%80\%99-fix-w orld $\% \mathrm{E} 2 \% 80 \% 9 \mathrm{D}$

Elmansy, R. (2020 ). Why Design Thinking Doesn't Work. https://www.designorate.com/why-design-thinking-doesnt-work/

Friis., D. R. (2020). Teo Yu, Siang. What is Design Thinking and Why Is It So Popular?”, Editonnextstep.Editonnextstep.1weekago.Web.

https://www.interaction-design.org/literature/article/what-is-design-thinking-and-why -is-it-so-popular

https://learningsolutionsmag.com/articles/a-designer-addresses-criticism-of-design-thi nking

Makhoul. (2018). Design Thinking Why Is It Important. Touch Innovation Program. https://tip.touch.com.lb/design-thinking-important/

Malamed, C. (2018). A Designer Addresses Criticism of Design. https://learningsolutionsmag.com/articles/a-designer-addresses-criticism-of-design-thi nking

PWR New Media (2019). Design Thinking-For Communications Professionals-How Design Thinking Processes Can Help You Shape Organizational Stories That Connect. https://www.pwrnewmedia.com/resource_center/PWR_whitepaper_design_thinking.p df

Tendar, M. (2020). Interview with Barry Katz, IDEO First Fellow, on Design. Thinking. https://www.fabernovel.com/en/insights/design-en/interview-with-barry-katz-ideos-fir st-fellow-on-design-thinking 